\title{
EDITORIAL
}

\section{What Its Human Component is Attempting for The Biosphere*}

T est anyone should think - even for a moment - that we visualize The Biosphere in the sense of 'the web of Life' or 'the totality of living matter', neither of which makes much biological sense, let us start by repeating our definition of it as 'The integrated living and life-supporting system comprising the peripheral envelope of Planet Earth together with its surrounding atmosphere so far down, and up, as any form of life exists naturally.' We recommend, and have ourselves long practised, capitalization of the initial letters of The Biosphere, which is basically a biogeochemical concept, and beg of non-biologists to recognize its biological component and so treat it.

Having I hope now finally satisfied ourselves as to what The Biosphere really is, let us attempt to answer the frequently-posed question of what we-now dangerously pandominant-humans are doing on behalf of this virtual totality of our life-support system (the 'virtual' being in deference particularly to the Sun's position far outside The Biosphere, which is nevertheless dependent on its energy-giving rays). But whether we think of The Biosphere in scientific terms as a defined entity or in more popular terms as our human and Nature's life-support system, we can now outline the following seven chosen examples of what we humans are attempting to do in its ultimate support.

1. A major thrust, coordinating global research and monitoring, is ICSU's International GeosphereBiosphere Programme: A Study of Global Change, the first part of which title we advocate writing with a hyphen to indicate a single or continuous body and thus reconcile with our above definition of The Biosphere. This important Programme, which seems to us far better termed simply (and in accordance with its major objective) 'A Study of Global Change', is now sufficiently widely known to make further explanation here seem unecessary, even though it is referred to in the latest Intecol Newsletter (18(2), p. 3, April 1988) as an 'as yet underused tool for collaborative research'. Here we merely express ardent hopes for its widest-possible use in our threatened world, and plead on behalf of the biologists that their vital interests be actively maintained inter alia in the proposed international transects and networks of observatories to monitor global changes.

2. In the course of last March's Vernadsky Commemoration activities in the USSR (see the Conferences \& Meetings section of this issue, pp. 187-9), there was established what we trust will be called and function as the International Vernadsky Foundation and be based on the Soviet Academy of Sciences' old headquarters in Leningrad. Details of its constitution, membership, and modus operandi, have yet to be worked out, but there is a strong demand - approved by acclamation by some 350 participants, including distinguished foreigners, at the terminal 'Round Table' roundup - that it embrace due reverence for life, with a 'main thrust of the healthful maintenance of The Biosphere' (see the Notes, News \& Comments section of this issue, p. 177).

3. Of further chosen activities on behalf of The Biosphere we propose to mention 5 in the order of their establishment. The first is UNESCO's Man and the Biosphere (MAB) programme, which was officially launched in 1971 as a practical, interdisciplinary follow-up of the International Biological Programme that, 'conceived in the early 1960s', was 'intended to be a major solution to important environmental and resource problems'. MAB emanated more immediately from the celebrated 'Biosphere Conference' (which had been held in Paris in 1968 under a tongue-twistingly prolix title) and centred around a considerable number of research themes that were concerned for example with human interactions with major ecobiomes-thus being involved primarily with meeting serious deficiencies in ecological knowledge and environmental understanding.

4. The next state, namely that of action, is most pertinently exemplified by MAB's practical offshoot of Biosphere Reserves, 'which now total 269 in 70 countries practically throughout the world. Each Biosphere Reserve consists of one or more core areas containing genetic materials in representative ecosystems that themselves need to be preserved. The core area (or areas) is surrounded by a delineated buffer-zone in which only activities compatible with the protection of the core area [or areas] may take place. These [activities] include, in particular, research into the structure and functioning of involved ecosystems under various management practices, as well as pertinent education and training or recreation and other uses carried out in accordance with management requirements and regulations. The buffer zone is normally itself surrounded by

\footnotetext{
* Based on a requested statement (following others by representatives of ICSU, UNESCO, UNEP, WHO, and IUCN) at the opening session of the SCOPE VII Triennial General Assembly, Budapest, Hungary, 6-10 June 1988-see the Conferences \& Meetings section of our next issue.
} 
a transition area where active participation of local people is sought, thus testing the economic and social applicability of the results achieved. Monitoring activities for a variety of purposes can be maintained in Biosphere Reserves, including the core area' (Michel Batisse, in litt. 19 May 1988).

5. The three remaining items were established specifically towards maintenance of The Biosphere as we conceive and define it and, at last, hope we begin to understand it. First in time was the World Campaign for The Biosphere, which is primarily an educational campaign to make people throughout the world know of, and learn everything possible about, The Biosphere and our utter dependence on it. This last is despite its 'delicate health' and widely deteriorating state, which indeed makes due action based on scientific knowledge all the more urgent. The Campaign grew out of earlier proposals for an 'International Year of, subsequently 'International Decade of', and then this continuing 'World Campaign For', The Biosphere, which last was finally declared in various countries on Environment Day (June 5th) of 1982, and was strongly supported by an 'Open Letter: To All Who Should Be Concerned' that had been signed by leaders in each of the world's six normally-inhabited continents. Most of these items were published, together with much other pertinent material, in our Journal, as seems best followed in its recent supplement Index of Titles and Authors in Environmental Conservation, 1974-86 (obtainable from our Secretariat for US $\$ 30$ or 45 Swiss francs, postage-paid, with likely free supplementation biennially henceforth).

6. Next in time was the World Council For The Biosphere (WCB), which was founded in Michigan in 1983 and consolidated in India the following year but is only now getting going with a full complement of 21 Councillors, an adopted Constitution (see pp. 176-7 of this issue), and an appointed Executive Secretary. Of its 7 major objectives, the first is 'Alerting decision-makers (in both Government and the private sector) to potential threats to the integrity of The Biosphere [and hence our life-support system] especially from human activity and, whenever and wherever possible, recommending measures to counter those threats.'

7. Our latest chosen item to become specifically geared to safeguarding The Biosphere was the International Conferences on Environmental Future, of which the first, held in Finland in 1971, had 15 listed items concerning The Biosphere (including a keynote paper) in its Index, while the second, held in Iceland in 1977, had 19 such items (including two sessional themes); but is was only in the third, held in Scotland in 1987, that the conferences became primarily geared to 'Maintenance of The Biosphere' (the title on that occasion). This was intended as a lead-in to a fourth, larger, Conference in the series, on the theme of 'Threats to The Biosphere and Imperative Countermeasures', which will take place in the Spring of 1990 provided we can find the necessary matching finances required by the would-be suitable host country, though meanwhile several other incipient invitations have been mooted.

Besides the above 7 chosen attempts inter alia to improve the lots of Man and Nature in our hard-pressed world, and assuming freedom from major nuclear strife or accident, there are of course others of usually more local regional, national, or institutional, natures-of which practically all must recognize that the basic problem is, widely and ever-increasingly, too many people.

Nicholas POLUNin 